\title{
INVESTIGATION ON MAGNETIC PROPERTIES AND CURIE TEMPERATURE OF SAMARIUM MODIFIED COBALT FERRITE
}

\author{
Sita Rama Raju Padam ${ }^{\mathrm{a}, \mathrm{b}}$ and Madhavaprasad Dasari ${ }^{\mathrm{c} *}$ \\ ${ }^{a}$ Department of BSH-Physics, Sri Vasavi Engineering College, \\ Tadepalligudem - 534 102, A.P., India
}

${ }^{b}$ Department of Physics, Rayalaseema University, Kurnool - 518 007, A.P., India

${ }^{c}$ Department of Physics, GIS, GITAM (deemed to be) University, Visakhapatnam - 530 045, A.P., India

\begin{abstract}
Samarium substituted cobalt ferrite $\mathrm{CoFe}_{2-\mathrm{x}} \mathrm{Sm}_{\mathrm{x}} \mathrm{O}_{4}$ with concentration of $\mathrm{x}=0,0.05$ and 0.15 were prepared using conventional solid-state ceramic method. Prepared samples first calcined at $900^{\circ} \mathrm{C}$ for 4 hours and then sintered at $1150{ }^{\circ} \mathrm{C}$ for 4 hours. The X-Ray powder diffraction data analysed to identify the phases present in the crystalline ceramic. An additional phase of Sm-Fe-O was observed for the sample at $x=0.15$. Lattice parameter, strain and saturation magnetization found to be decreasing whereas crystallite size and coercivity found to be vary with samarium content. Decrease of Curie temperature attributed to the decrease of exchange interaction among tetrahedral or octahedral ions due to samarium content.
\end{abstract}

Keywords: Cobalt Ferrite; X-Ray diffraction; Microstructure; Magnetic properties

\section{Introduction}

Rare earth doped cobalt ferrite shows changes in structural, magnetic and other absorption characteristics. ${ }^{1}$ Doping rare earth metals with higher ionic radii in spinel cobalt ferrites can cause changes in crystallite sizes and

\footnotetext{
* Madhavaprasad Dasari, e-mail: madhavaprasaddasari@gmail.com
} 
lower particle size. ${ }^{2}$ Traditional rare earth metals replace iron, as it is the general practice and lead to distortion or strain in spinel ferrites. ${ }^{3}$ This results in moderating magnetic properties depending on the individual magnetic moments. ${ }^{4}$ Dilution of magnetic moments further effects the exchange interactions, lowers Curie temperature and acquires ability to tailor the material for desired application.

Samarium has tendency to occupy octahedral sites and its presence lowers the net magnetic moment. The use of samarium in Ni-Co ferrites lowers the saturation magnetization due to lowering of exchange interaction among the ions. ${ }^{5}$ Cobalt ferrite with strong magnetic behavior due to high coercivity, high Curie temperature, magneto crystalline anisotropy and mechanical harness. The use of samarium in cobalt ferrite replacing iron can result in lowering the magnetic properties, and Curie temperature. In present investigation, we attempted to investigate the effect of samarium on magnetic properties and Curie temperature in $\mathrm{CoFe}_{2-\mathrm{x}} \mathrm{Sm}_{\mathrm{x}} \mathrm{O}_{4}$.

\section{Experimental}

Polycrystalline $\mathrm{CoFe}_{2-\mathrm{x}} \mathrm{Sm}_{\mathrm{x}} \mathrm{O}_{4}$ ceramics were prepared using conventional solid state sintering technique. Raw materials of cobalt oxide, ferric oxide and samarium oxide are used in stoichiometry proportional and thoroughly mixed, calcined in powder form at $900{ }^{\circ} \mathrm{C}$ for $4 \mathrm{~h}$. The powders were again grinded and sintered at $1150{ }^{\circ} \mathrm{C}$ for $4 \mathrm{~h}$ to obtain $\mathrm{CoFe}_{2-\mathrm{x}} \mathrm{Sm}_{\mathrm{x}} \mathrm{O}_{4}$ (for $\mathrm{x}=0,0.05,0.15$ ). The XRD phase examined by using Bruker D8 SSS X-ray diffraction diffractometer (XRD) using $\mathrm{Cu}-\mathrm{K} \alpha$ radiation. The microstructures of samples were characterized with a scanning electron microscope (SEM) (JEOL JSM-5600, Tokyo, Japan). Magnetic measurements were carried out using a 9 T PPMS based VSM (Quantum Design). 


\section{Results and Discussion}

Figure 1 (a) shows the XRD pattern that show sharp and well-defined peaks for polycrystalline Sm-doped Cobalt ferrites $(\mathrm{x}=0,0.05)$. Polycrystalline nature of the samples is evident from the existence of main peaks in spinel ferrites across the diffraction angle. It appears that 311 peak appears to be shifting slightly towards lower angles $(2 \theta)$ values with increase in Sm content. This indicates that Sm with higher ionic radii $\left(\mathrm{r}_{\mathrm{Sm}}=0.94 \AA\right)$ is incorporated into spinel matrix replacing iron with $\left(\mathrm{r}_{\mathrm{Fe}}=0.64 \AA\right)$. The displacement of ferrite to lower angles results in the formation of garnet phase involving diffusion of iron oxide to grain boundaries and causes reaction with samarium oxide $\left(\mathrm{Sm}_{2} \mathrm{O}_{3}\right)$. This results in the dissolution of $\mathrm{Sm}_{2} \mathrm{O}_{3}$ causing shrinking of unit cell, lowering lattice parameter, increasing strain and causing appearance of $\mathrm{FeSmO}_{3}$ peak ${ }^{6}$ as observed in Figure1 (b).

Appearance of $\mathrm{FeSmO}_{3}$ peak occurred only for higher concentration of $\mathrm{Sm}$ at $\mathrm{x}=0.15 . \mathrm{FeSmO}_{3}$ peak did not appear in low concentration of Smdoped cobalt ferrites. ${ }^{7}$ The absence of such peak for lower concentration for Sm indicates the ability of accommodation of unit cell upto certain extent for rare earth metals. Lattice parameter decreases with the increase in Sm and the variations of crystallite size may be observed depending on Sm concentration in Cobalt ferrite, tabulated in table 1. Increase of strain is due to the presence of heavy metals and thus the increase in molecular weight is faster than that of volume of unit cell. 

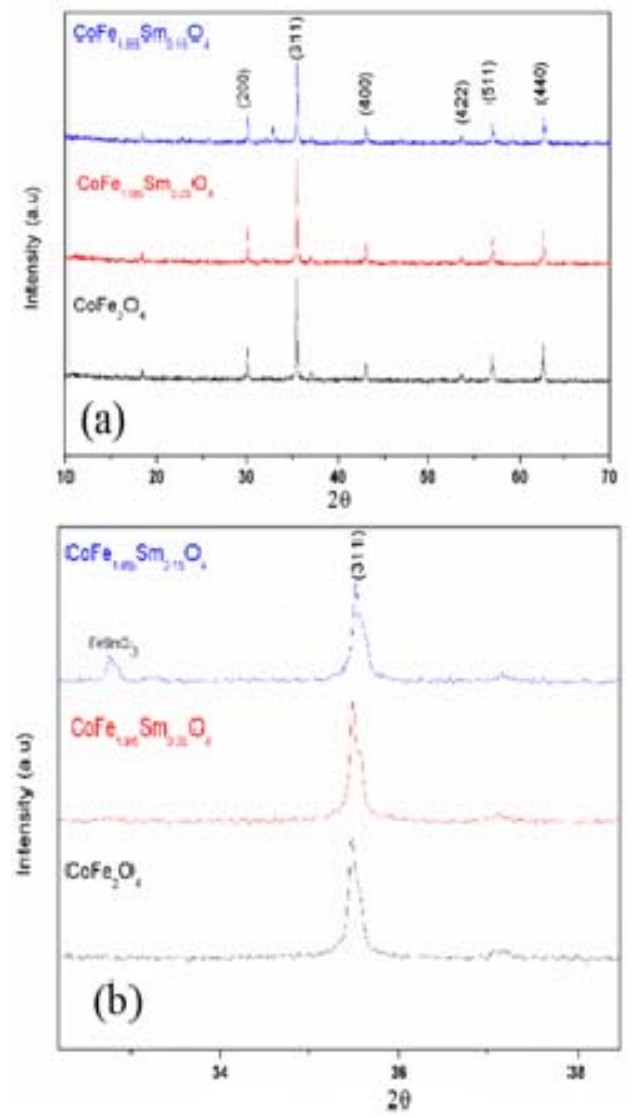

Figure 1. XRD patterns of unsubstituted and Sm substituted Cobalt ferrite.

Table 1. Lattice parameter, crystallite size and strain size for Sm-doped Cobalt ferrites.

\begin{tabular}{cccc}
\hline $\begin{array}{c}\text { Composition } \\
\mathrm{CoFe}_{2-}\end{array}$ & $\begin{array}{c}\text { Lattice } \\
\text { parameter } \\
\mathrm{Sm}_{\mathrm{x}} \mathrm{O}_{4}\end{array}$ & $\begin{array}{c}\text { Crystallite } \\
\text { size } \\
(\AA)\end{array}$ & $\begin{array}{c}\text { Strain } \\
(\AA)\end{array}$ \\
\hline $\mathrm{x}=0$ & 8.389051 & 1116.9098 & $1.0251955 \mathrm{E}-7$ \\
$\mathrm{x}=0.05$ & 8.385238 & 1000.2195 & $1.4804201 \mathrm{E}-5$ \\
$\mathrm{x}=0.15$ & 8.379049 & 1130.3597 & $3.0240894 \mathrm{E}-4$ \\
\hline
\end{tabular}

Figure 2 shows the SEM pictures of $\mathrm{CoFe}_{2-\mathrm{x}} \mathrm{Sm}_{\mathrm{x}} \mathrm{O}_{4}(\mathrm{x}=0.0,0.05$, 0.15 ) sintered at $1150{ }^{\circ} \mathrm{C}$. The decrease in grain size with increase in samarium concentration (table 2) has been observed. This decrease can be 
attributed to the sintering behaviour of Sm doped Co-ferrite. The appearance of secondary phase increases stress at the grain boundaries and leads to decrease in grain size.
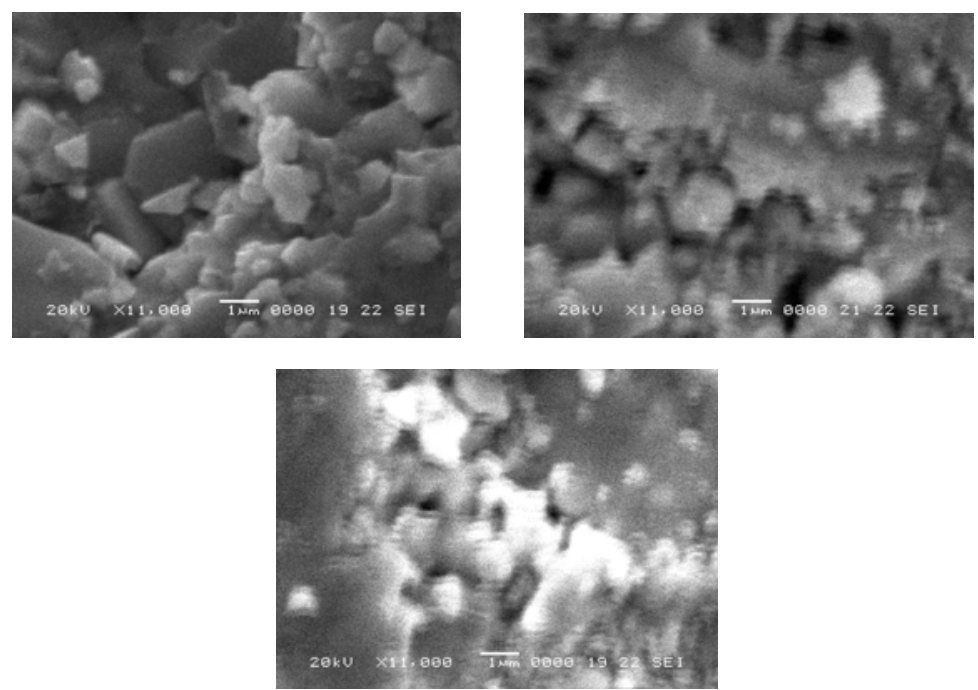

Figure 2. Scanning Electron Micrographs of $\mathrm{CoFe}_{2-\mathrm{x}} \mathrm{Sm}_{\mathrm{x}} \mathrm{O}_{4}(\mathrm{x}=0,0.05,0.15)$.

Table 2. Grain Size of $\mathrm{CoFe}_{2-\mathrm{x}} \mathrm{Sm}_{\mathrm{x}} \mathrm{O}_{4}$.

\begin{tabular}{cc}
\hline Composition $\mathrm{CoFe}_{2-\mathrm{x}} \mathrm{Sm}_{\mathrm{x}} \mathrm{O}_{4}$ & $\begin{array}{c}\text { Grain Size } \\
(\mu \mathrm{m})\end{array}$ \\
\hline $\mathrm{x}=0$ & 1.176 \\
$\mathrm{x}=0.05$ & 1.106 \\
$\mathrm{x}=0.15$ & 0.991 \\
\hline
\end{tabular}

Figure 3 Shows the magnetic hysteresis graph for $\mathrm{CoFe}_{2-\mathrm{x}} \mathrm{Sm}_{\mathrm{x}} \mathrm{O}_{4}$ $(\mathrm{x}=0,0.05,0.15)$ for samples sintered at $1150{ }^{\circ} \mathrm{C}$. Figure 2 shows normal trend of increase of magnetization with the increase of magnetic field saturating up to $10 \mathrm{kOe}$ for all samples even when magnetic field was extended up to $50 \mathrm{kOe}$. Doping rare earth metal such as $\mathrm{Sm}$ decreases 
saturation magnetization due to paramagnetic nature and lowers magnetic moment, as per our previous investigation. ${ }^{5}$

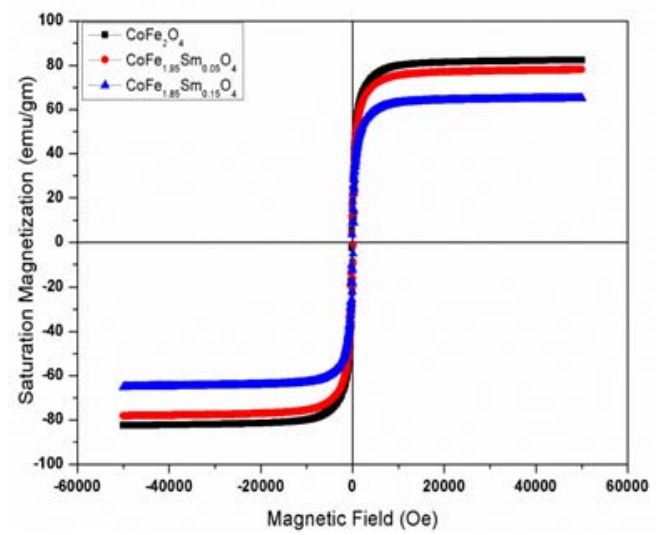

Figure 3. Magnetic Hysteresis of $\mathrm{CoFe}_{2-\mathrm{x}} \mathrm{Sm}_{x} \mathrm{O}_{4}$.

Decrease of saturation magnetization with the increase in Sm content, as shown in table 3 , indicate the dilution of magnetic moment contribution due to non-magnetic ions. High concentration of samarium doping may cause migration of cobalt present in octahedral sites towards tetrahedral site, lowering the net magnetization, as observed in higher $\mathrm{Sm}$ content. The substitution of $\mathrm{Sm}^{3+}$ replacing $\mathrm{Fe}^{3+}$ in the octahedral sites reduces the $\mathrm{Fe}^{3+}-\mathrm{Fe}^{3+}$ exchange interactions, thus lowering net magnetization, as per Neel's model. ${ }^{8-9}$

Table 3. Magnetic properties of $\mathrm{CoFe}_{2-\mathrm{x}} \mathrm{Sm}_{\mathrm{x}} \mathrm{O}_{4}$.

\begin{tabular}{cccc}
\hline $\begin{array}{c}\text { Composition } \\
\mathrm{CoFe}_{2-}\end{array}$ & $\begin{array}{c}\text { Saturation } \\
\text { Magnetization } \\
\mathrm{Sm}_{\mathrm{x}} \mathrm{O}_{4}\end{array}$ & $\begin{array}{c}\text { Coercivity } \\
(\mathrm{emu} / \mathrm{gm})\end{array}$ & $\begin{array}{c}\text { Curie } \\
\mathrm{Hc}(\mathrm{Oe})\end{array}$ \\
$\begin{array}{c}\text { temperature } \\
(\mathrm{K})\end{array}$ \\
$\mathrm{x}=0$ & 82.425 & 155.01 & 720.61 \\
$\mathrm{x}=0.05$ & 78.086 & 210.99 & 712.71 \\
$\mathrm{x}=0.15$ & 65.034 & 179.28 & 641.18 \\
\hline
\end{tabular}


Increase in coercivity (table 3) was observed for Sm doped cobalt ferrite is due to rising of coupling behaviour from magneto-crystalline anisotropy. Further, the decrease of coercivity is due to lowering iron ions $\left(\mathrm{Fe}^{3+}\right)$ which decrease anisotropy field, due to which domain wall energy is also lowered. ${ }^{10-11}$ It is known that coercivity is related with magnetization, which can be observed from the relation: ${ }^{12}$

$$
H_{c}=\frac{0.64 \times K}{M_{s}}
$$

Variation of magnetization with temperature under magnetic field of 100 Oersted was plotted in Figure 4 for further investigation. The investigation reveals that with the increase in Sm concentration, Curie temperature has decreased and corresponding values have been plotted in the table 3 . Lowering ratio of iron replacing non-magnetic Sm can effectively reduce the magnetization rising from individual sites. Samarium's magnetic moment with $1.7 \mu_{\mathrm{B}}$ Bohr magneton rising from $4 \mathrm{f}$ electrons replacing iron in octahedral, can cause magnetic variations. Sm increase can cause disruption among $\mathrm{Co}-\mathrm{Fe}$ ions or $\mathrm{Fe}-\mathrm{Fe}$ ions or secondary phase formation can lead to lower exchange energies. This effectively reduces the pinning effects of the rising from cobalt or iron, lowering the net contribution for magnetic moments or magnetization, further lowering Curie temperature. Abnormal path followed by the state of magnetization observed in $\mathrm{x}=0.05$ content of $\mathrm{Sm}$ in cobalt ferrite, as shown in Fig. 3 when compared with unsubstituted cobalt ferrite. For $\mathrm{Sm}=0.05$, the abrupt rise and fall in the state magnetization in the same vicinity zone of cobalt ferrite suggests the lowering exchange interaction among magnetic ions due to samarium. Only $\Delta \mathrm{T}=8 \mathrm{~K}$ change was observed from basic cobalt ferrite sample with $\mathrm{x}=0.05$ but significant change of $\Delta \mathrm{T}=80 \mathrm{~K}$ for $\mathrm{x}=0.15$ samarium content can also 
be observed. Lowering exchange energies from individual sites can be understood on path followed by the state of magnetization with respect to temperature, which is evident due to Sm doping. In previous reports, it has been shown that the decrease in Curie temperature enables operation within the temperature range of reversible magneto-mechanical response. In another study by B. Chandra Sekhar et al high strain derivative, moderate values of maximum magnetostriction and saturation magnetization and low Curie temperature as a good sensing material has been obtained. Based on these studies, it can be said that the decrease in Curie temperature along with considerable increase in coercivity in the present study make Sm doped Co-ferrites suitable for magnetostrictive applications. ${ }^{13,14}$

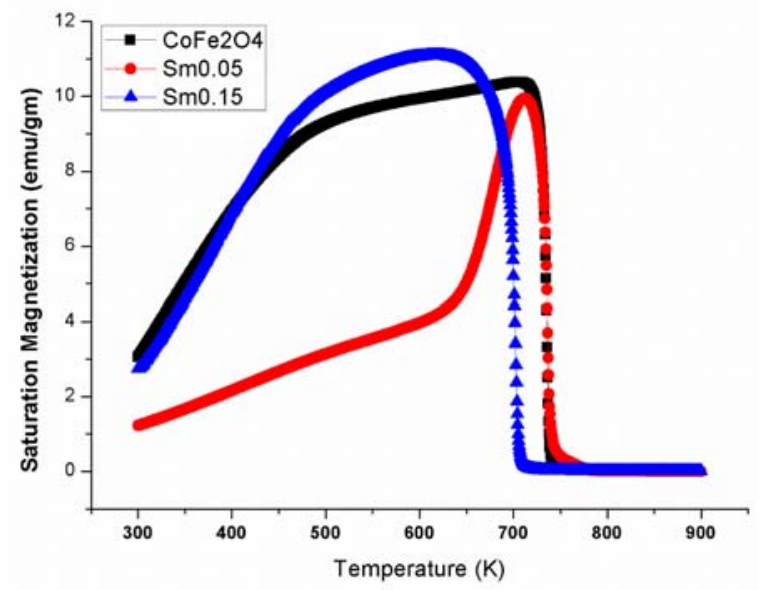

Figure 4. Magnetization versus temperature for $\mathrm{CoFe}_{2-\mathrm{x}} \mathrm{Sm}_{\mathrm{x}} \mathrm{O}_{4}$.

\section{Conclusions}

Samarium doped cobalt ferrite prepared with solid state ceramic method. Powders calcined at $900{ }^{\circ} \mathrm{C}$ for 4 hours and then sintered at $1150{ }^{\circ} \mathrm{C}$ for 4 hours for phase formations. XRD studies identified addition phase of $\mathrm{Sm}-\mathrm{Fe}-\mathrm{O}_{3}$ for $\mathrm{x}=0.15$ samarium content and lattice parameter was found to be decreasing with the increase in samarium. Dilution of magnetic properties 
was understood based on lower exchange interactions and low magnetic nature of samarium which, in turn caused reduction of saturation magnetization and Curie temperature.

\section{Acknowledgements}

We thank Dr. P.D Babu for extending VSM (M-H, M-T) measurements at UGC-DAE Consortium for Scientific Research, Mumbai center, R5-shed, BARC, Mumbai-400 085. We also like to thank Dr. Mukul Gupta of UGC-DAE Consortium for Scientific Research, Indore for extending the XRD facility and their support.

\section{References}

1. Fuxiang, C.; Chunsheng, L.; Junfeng, K.; Zhigang, X.; Chunhua, Y. Nanostructure magneto-optical thin films of rare earth $(\mathrm{RE}=\mathrm{Gd}, \mathrm{Tb}, \mathrm{Dy})$ doped cobalt spinel by sol-gel synthesis. J. Appl. Phys. 1999, 85, $2782-2786$.

2. Rezlescu, N.; Rezlescu, E.; Pasnicu, C.; Craus, M. L. Effects of the rare-earth ions on some properties of a nickel-zinc ferrite. J. Phys. Condens. Matter. 1994, $6,5707$.

3. Zhou, Y.W.; Zhang, C.S.; Liao, C.H.; Yan, L.Y.; Chen, S.Y. Rare-earth-mediated magnetism and magneto-optical Kerr effects in nanocrystalline $\mathrm{CoFeMn}_{0.9} \mathrm{RE}_{0.1} \mathrm{O}_{4}$ thin films. J. Magn. Magn. Mater. 2004, 280, 327-333.

4. Bulai, G.; Diamandescu, L.; Dumitru, I.; Gurlui, S.; Feder, M.; Caltun, O. F. Effect of rare earth substitution in cobalt ferrite bulk materials. J. Magn. Magn. Mater. 2015, 390, 123-131.

5. Arun Kumar, C.H.; Ganapathi Rao, G.; Samatha, K.; Bharadwaj, S.; Dasari, M. P. Observation on magnetic variation for low concentration of bismuth and samarium doped Ni-Co ferrites. Karbala Int. J. Mod. Sci. 2018, 4, 143-150. 
6. Mahmoudi, M.; Kavanlouei, M.; Maleki-Ghaleh, H. Effect of Composition on Structural and Magnetic Properties of Nanocrystalline Ferrite $\mathrm{Li}_{0.5} \mathrm{Sm}_{\mathrm{x}} \mathrm{Fe}_{2.5-\mathrm{x}} \mathrm{O}_{4}$. Powder Metall. Met. Ceram. 2015, 54, 31-39.

7. Ahmed, M. A.; Okasha, N.; Mohamed, A. A.; Mmdouh, I. Optimizing the structure and magnetic properties of SmCo nanoferrites synthesized by autocombustion processing techniques. J. Magn. Magn. Mater. 2014, 358, 32-37.

8. Ne'el, L. Remarks on the theory of the magnetic properties of thin layers and fine grains. J. Phys. Rad. 1956, 17, 250-255.

9. Del Bianco, L.; Fiorani, D.; Testa, A. M.; Bonetti, E.; Savini, L.; Signoretti, S. Magnetothermal behaviour of a nanoscale $\mathrm{Fe} / \mathrm{Fe}$ oxide granular system. Phys. Rev. B. 2002, 66, 174418.

10. Cullity, B. D. Introduction to Magnetic Materials, Addison-Wesley, Reading, MA, USA, 1972.

11. Yakovlev, L. M.; Rubalikaya, E. V.; Lapovok, N. Ferromagnetic Resonance in Lithium Ferrite. Soviet Phys. Solid State 1969, 10, 2301-2303.

12. Laureti, S.; Varvaro, G.; Testa, A. M.; Fiorani, D.; Agostinelli, E.; Piccaluga, G.; Musinu, A.; Ardu, A.; Peddis, D. Magnetic interactions in silica coated nanoporous assemblies of $\mathrm{CoFe}_{2} \mathrm{O}_{4}$ nanoparticles with cubic magnetic anisotropy. Nanotechnology 2010, 21, 315701.

13. Caltun, O.; Rao, G. S. N.; Rao, K. H.; Parvatheeswara Rao, B.; Dumitru, I.; Chong-Oh, K.; Kim, C. G. The influence of Mn doping level on magnetostriction coefficient of cobalt ferrite. J. Magn. Magn. Mater. 2007, 316, e618-e620.

14. Chandra Sekhar, B.; Rao, G. S. N.; Caltun, O. F.; Dhana Lakshmi, B.; Parvatheeswara Rao, B.; Subba Rao, P. S. V. Magnetic and magnetostrictive properties of $\mathrm{Cu}$ substituted Co-ferrites. J. Magn. Magn. Mater. 2016, 398, 59-63. 